NBER WORKING PAPER SERIES

\title{
DISTRIBUTIONAL EFFECTS OF AIR POLLUTION FROM ELECTRIC VEHICLE ADOPTION
}

\author{
Stephen P. Holland \\ Erin T. Mansur \\ Nicholas Z. Muller \\ Andrew J. Yates \\ Working Paper 22862 \\ http://www.nber.org/papers/w22862
}

\author{
NATIONAL BUREAU OF ECONOMIC RESEARCH \\ 1050 Massachusetts Avenue \\ Cambridge, MA 02138 \\ November 2016
}

We would like to thank Meghan Busse and participants at the NBER conference on Energy Policy Tradeoffs between Economic Efficiency and Distributional Equity. We would also like to thank Stephen Gaughan for generating the GIS distance data used in this analysis. The views expressed herein are those of the authors and do not necessarily reflect the views of the National Bureau of Economic Research.

At least one co-author has disclosed a financial relationship of potential relevance for this research. Further information is available online at http://www.nber.org/papers/w22862.ack

NBER working papers are circulated for discussion and comment purposes. They have not been peer-reviewed or been subject to the review by the NBER Board of Directors that accompanies official NBER publications.

(C) 2016 by Stephen P. Holland, Erin T. Mansur, Nicholas Z. Muller, and Andrew J. Yates. All rights reserved. Short sections of text, not to exceed two paragraphs, may be quoted without explicit permission provided that full credit, including $\odot$ notice, is given to the source. 
Distributional Effects of Air Pollution from Electric Vehicle Adoption

Stephen P. Holland, Erin T. Mansur, Nicholas Z. Muller, and Andrew J. Yates

NBER Working Paper No. 22862

November 2016

JEL No. H23,Q4,Q5

\begin{abstract}
$\underline{\text { ABSTRACT }}$
We examine the distributional effects of changes in local air pollution from driving electric vehicles in the United States. We employ an econometric model to estimate power plant emissions and an integrated assessment model to value damages in air pollution from both electric and gasoline vehicles. Using the locations of currently registered electric vehicles, we find that people living in census block groups with median income greater than about $\$ 65,000$ receive positive environmental benefits from these vehicles while those below this threshold receive negative environmental benefits. Asian and Hispanic residents receive positive environmental benefits, but White and Black residents receive negative environmental benefits. In multivariate analyses, environmental benefits are positively correlated with income and urban measures, conditional on racial composition. In addition, conditional on income and urbanization, separate regressions find environmental benefits to be positively related with Asian and Hispanic block-group population shares, negatively correlated with White share, and uncorrelated with Black share. Environmental benefits tend to be larger in states offering purchase subsidies. However, for these states, an increase in subsidy size is associated with a decrease in created environmental benefits.
\end{abstract}

Stephen P. Holland

Bryan School of Business and Economics University of North Carolina, Greensboro P.O. Box 26165

Greensboro, NC 27402-6165

and NBER

sphollan@uncg.edu

Erin T. Mansur

Dartmouth College

100 Tuck Hall

Hanover, NH 03755

and NBER

erin.mansur@dartmouth.edu
Nicholas Z. Muller

Department of Economics

Warner Hall, 305D

Middlebury College

303 College Street

Middlebury, VT 05753

and NBER

nicholas.muller74@gmail.com

Andrew J. Yates

Department of Economics

and Curriculum for the

Environment and Ecology

University of North Carolina at Chapel Hill

CB 3305

Chapel Hill, NC 27599

ajyates@email.unc.edu 


\section{Introduction}

Public polices create benefits (both positive and negative) which accrue to various individuals in the economy. A thorough accounting of how these benefits are distributed by income and race provides an important context to evaluate the efficacy of public policies, and indeed such an accounting is explicitly required for federal environmental programs (Banzhaf 2011). In this paper, we examine the distributional effects of the change in local air pollution that results from electric vehicle adoption.

Our analysis of this issue is timely and important for three reasons. First, there is a vast array of public policies that encourage the development of the market for electric vehicles. For example, the Federal government offers significant subsidies for purchasing electric vehicles ${ }^{1}$ and tax credits for electric vehicle infrastructure 2 Policies at the state and local leve 3 offer additional purchase subsidies and tax credits for infrastructure, as well as sales tax exemptions, discounted electricity for charging electric vehicles, HOV lane access, and smog check exemptions 4 Second, electric vehicles have different effects on air pollution across locations. As of June 2014, there were approximately 130,000 electric vehicles registered in the contiguous United States. These registrations provide evidence on the spatial distribution of the propensity for electric vehicle adoption. Third, although there is a growing literature relating air pollution and electric vehicles, little is known about the characteristics of those who are most affected by the fleet of electric vehicles.

When an electric vehicle is adopted, there is a change in air pollution relative to what would have been emitted by the forgone gasoline vehicle. Gasoline vehicles have tailpipe

\footnotetext{
${ }^{1}$ Internal Revenue Code Section 30D (Notice 2009-89) provides a tax credit of up to $\$ 7500$.

${ }^{2}$ See Public Law 114-94 - FAST Act.

${ }^{3} \mathrm{~A}$ complete list of state and local incentives is described at http://www.afdc.energy.gov/laws/.

${ }^{4}$ There are many other examples. The Department of Energy EV Everywhere Challenge, which is a multifaceted program with the goal of making electric vehicles "as affordable and convenient" as gasoline vehicles within the next decade (energy.gov/eere/vehicles/ev-everywhere-grand-challenge-does-10-year-vision-plugelectric-vehicles). The California Zero Emission Vehicle Program requires a fraction of vehicles sold in the state to have zero tailpipe emissions (http://www.arb.ca.gov/msprog/zevprog/zevprog.htm). CAFE standards assign electric vehicles a generous mpg equivalent and sometimes give electric vehicles sales extra weight in the calculation of the standard (Jenn et al., 2016). Even seemingly unrelated policies, such as the settlement with Volkswagen for excess emissions of $\mathrm{NO}_{\mathrm{X}}$ from diesel vehicles, provide a boost for electric vehicles (https://www.vwdieselinfo.com/updates/statement-by-volkswagen-group-of-america-7/ states that Volkswagen will "invest $\$ 2.0$ billion over 10 years in zero emissions vehicle (ZEV) infrastructure, access and awareness initiatives").
} 
emissions and non-exhaust emissions such as from tire and road wear. Electric vehicles cause non-exhaust emissions and smokestack emissions from the electric power plants that charge them 5 The emerging consensus from the literature that quantifies and compares the emissions from electric and gasoline vehicles 5 is that, on average, electric vehicles tend to reduce $\mathrm{CO}_{2}$ emissions but increase local pollution such as $\mathrm{SO}_{2}$ and $\mathrm{PM}_{2.5}$. However, there is considerable variation around these averages, such that in some places electric vehicles have significant positive effects and in other places significant negative effects.

This finding suggests it is critical to account for local factors when determining distributional effects due to electric vehicle adoption. Correspondingly, our analysis has three main components. First, we use vehicle registration data to identify the locations in which the electric vehicles are driven. These data represent a combined private and policy revealed preference for electric vehicle adoption. Second, we determine the environmental benefits from driving electric vehicles, which are defined as the difference in air pollution damages between driving an electric vehicle and driving the forgone gasoline vehicle. Air pollution damages from the forgone gasoline vehicle depend on its location. Air pollution damages from the electric vehicle depend on the locations of the vehicle and the generating plants powering it. We follow the methodology in Holland et al., (2016) to determine these damages. Importantly, we analyze the geographic pattern of the environmental benefits at the county level. That is, we track the dispersion of pollutants produced by both gasoline and electric vehicles, which differs because of the height of emissions, wind patterns, and the distributed nature of the electricity grid. This leads to a matrix which specifies the environmental benefits that accrue to county $j$ from driving the electric vehicle rather than the forgone gasoline vehicle in county $i$. The third major component is data on demographics of the affected populations at the census block group level.

This paper examines an important distinction between environmental benefits created and environmental benefits received. Created environmental benefits account for the fact that driving in a given county creates air pollution in other counties. Received environmental

\footnotetext{
${ }^{5}$ In addition, there are life-cycle emissions from manufacturing the vehicles and developing the fuel sources. In this paper we focus on emissions from driving and charging the vehicles as these emissions vary significantly depending on where the vehicle is driven.

${ }^{6}$ See for example Babaee et al (2014), Graff Zivin et al (2014), Michalek et al (2011), Tessum et al (2014), Grissom (2013), Archsmith et al., (2015), Holland et al., (2016), Yuksel et al., (2016).
} 
benefits reflect the fact that the air pollution damage received in a given county is affected by driving in many counties. Loosely speaking, this difference amounts to vertical rather than horizontal summation of the matrix of environmental benefits. Our distributional analysis focuses primarily on the received environmental benefits but created environmental benefits indicate the source of any benefits.

Created environmental benefits have been well studied in the general literature on spatial effects of air pollution (Mendelsohn, 1980; Banzhaf et al., 2004; Fann et al., 2009; Muller and Mendelsohn, 2009) as well as in the specific comparison of gasoline and electric vehicles (Michalek et al., 2011; Holland et al., 2016). This emphasis is natural for both policy design and cost-benefit analysis. Consider the decision to adopt an electric vehicle in a particular county. From the perspective of benefit-cost analysis, what matters are all of the impacts associated with that choice - whether they manifest in the same location as the consumer that bought the electric vehicle or not. From the perspective of policy design (and incidence on the taxed or regulated), created environmental benefits are appropriate for the calibration of Pigouvian taxes, for example. Consumers of transportation services then face the full (geographically aggregated) cost of driving. Intuitively, the pattern of incidence of the Pigouvian tax (the relative magnitudes of the tax rates across jurisdictions) reflects the marginal damage of driving, by location of the vehicle.

In this paper, we highlight the importance of using received environmental benefits to describe distributional effects. We explore policy-relevant questions in three areas: traditional measures of inequality applied to environmental benefits, environmental benefits decomposed by income groups, and environmental benefits categorized by racial and ethnic groups. Using the metric of received benefits, we find that both gasoline and electric vehicles yield damages that are less equally distributed than median household income across census block groups. And damages from gasoline vehicles are more concentrated than those from electric vehicles. Given that emissions from gasoline vehicles are released at ground level in the proximity of exposed populations whereas discharges from power stations (often located in rural areas) are used to fuel electric vehicles, this finding is quite intuitive.

We next relate received benefits to income of the exposed populations. While electric vehicle damages are quite uniformly distributed across income groups, adverse effects from our 
forgone gasoline vehicles are greater among higher income populations. As a consequence, the benefits from electric vehicle adoption are increasing in income. Census block groups with median income greater than about $\$ 65,000$ receive positive environmental benefits from electric vehicle adoption whereas block groups with income less than this threshold receive negative environmental benefits. This regressivity, we note, is defined in terms of environmental benefits which is distinct from the distribution of federal subsidies for electric vehicles (see Borenstein and Davis (2015)).

Our final distributional analysis applies the received benefits approach to characterizations of communities by race and ethnicity. This dimension of the analysis reveals that while Black and White populations incur negative benefits on average from electric vehicle adoption, Hispanic and Asian communities enjoy positive benefits on average. This pattern of incidence is consistent with the facts that Hispanic and Asian population densities are highest in the West and that electric vehicles tend to be beneficial when used in the West.

There are several caveats to our work. First, any attempt to estimate the damages from air pollution is rife with uncertainty. This manifests throughout the underlying integrated assessment model, from the connection between emissions and air pollution concentrations, to the implications of concentrations on human health, and to the monetary value attributed to non-market entities such as mortality risk. These uncertainties are not unique to the present work. Nonetheless, they are important to note. Second, we make several assumptions about vehicle use that depart from consumers' actual behavior. For example, we assume a fixed amount of total miles driven per year across all locations and vehicles are driven exclusively in the county of registration. Although we vary this last assumption in a sensitivity analysis, we do not account for long distance travel. Importantly, we apply these assumptions to both electric vehicles and gasoline vehicles. Third, because of the large number of policies affecting electric vehicle adoption and their interconnected nature, we consider the suite of policies which affect consumers' decisions regarding vehicle adoption en masse. Rather than trying to disentangle the effects of the various policies, we simply take as given that the collection of policies as a whole does indeed increase electric vehicle adoption and thus is at least partially responsible for the distributional effects that we identify.

That said, the federal and state purchase subsidies for electric vehicles are large and 
highly visible, and are therefore deserving of study in their own right. Indeed, Li et al., (2015) estimate that fifty percent of electric vehicle adoptions can be attributed to these subsidies. Borenstein and Davis (2015) use federal tax return data to show that the vast majority of the pecuniary benefits of the federal subsidy accrue to wealthy individuals. We add to this literature on purchase subsidies by analyzing the relationship between environmental benefits and purchase subsidies. For this analysis, created environmental benefits are the appropriate measure. Conditional on a state offering purchase subsidies, an increase in subsidy size is associated with a decrease in created environmental benefits.

In Section 2 we describe our procedure for determining the air pollution damages from electric vehicles and the foregone gasoline vehicles. In Section 3 we describe the distribution effects of electric vehicle adoption. In Section 4 we analyze the relation between purchase subsides and environmental benefits. Section 5 concludes.

\section{Air Pollution Damages from Electric Vehicle Driving}

\subsection{Electric Vehicle Registrations}

The market for electric vehicles reemerged in 2010 with the introduction of the Nissan Leaf 7 The market is rapidly expanding with over a dozen models currently for sale. In recent years, sales of electric vehicles have exceeded 50,000 units per year, corresponding to approximately 0.3 percent of U.S. light duty vehicle sales.

Our data on electric vehicles registered in the contiguous US as of June 2014 include nine electric vehicle models and approximately 130,000 vehicles 8 These registrations are summarized in Table 1. Panel A lists each electric vehicle model. Panel A also reports the distribution of electric vehicles by census region. Over half of the vehicles are registered in the West, and approximately 25 percent are in the South. Of the nine electric vehicle models, two models (the Nissan Leaf and Tesla S) account for over $80 \%$ of the vehicles.

\footnotetext{
${ }^{7}$ In this paper, we use the term electric vehicles to denote pure electric vehicles that are powered only by electricity. This is in contrast to plug-in-hybrid vehicles like the Chevrolet Volt that uses both electricity and gasoline. Approximately equal numbers of pure electric vehicles and plug-in-hybrid vehicles have been sold in recent years.

${ }^{8}$ We obtained proprietary data on electric vehicle registration data from IHS Automotive.
} 
These two models are distributed throughout the country, but other models (sometimes called "compliance cars") are located primarily in the West especially in California. Panel B shows that most vehicles are registered in urban counties, and Panel C lists the Metropolitan Statistical Areas (MSAs) with the most electric vehicle registrations. More electric vehicles are registered in the Atlanta MSA than in any other city. One reason for this may be that Georgia had a large purchase subsidy in place until recently. Seven of the ten highest registration MSAs are in California, which reflects the relatively high penetration of electric vehicles in California and the West.

Because we want to calculate the environmental benefit from driving electric vehicles, our data would ideally identify the number of miles driven and the exact location of these miles for both the electric vehicles and the forgone gasoline vehicles. In lieu of these data, for our baseline calculations we assume that each vehicle is driven 15,000 miles per year and that each vehicle is driven exclusively in the county where it is registered. We consider the effects of changing the latter assumption in the sensitivity analysis.

\subsection{Calculating Damages from Air Pollution}

To determine the environmental benefits of driving an electric vehicle, we calculate the air pollution damages from driving the electric vehicle and the air pollution damages from driving the forgone gasoline vehicle. The environmental benefit of the electric vehicle is equal to the damages from driving the forgone gasoline vehicle minus the damages from driving the electric vehicle. If this number is positive, then it indicates that moving from the forgone gasoline vehicle to the electric vehicle decreases air pollution damages. The methodology we use is described in detail in Holland et al., (2016). Here we sketch an overview. Because we are interested in distributional issues, we focus on local pollutants and ignore global pollutants such as $\mathrm{CO}_{2} \cdot 9$

For each electric vehicle, we created a "composite" forgone gasoline vehicle that reflects consumer preferences. We obtained survey data from the market research firm MaritzCX

\footnotetext{
${ }^{9}$ Holland et al (2016) show the distribution of environmental benefits from global pollutants and local pollutants across counties. The average for global pollutants is small and positive while the average for local pollutants is large and negative. In addition, the variance is greater for local pollutants.
} 
Table 1: Locations of Registered Electric Vehicles

Panel A: Vehicle counts by Census Region \& Model

\begin{tabular}{lrrrrr}
\hline Electric & & & & & \\
Vehicle & Midwest & Northeast & South & West & Total \\
\hline Chevy Spark & 44 & 3 & 24 & 1,828 & 1,899 \\
Fiat 500 & 28 & 2 & 76 & 8,449 & 8,555 \\
Ford Focus & 342 & 345 & 650 & 3,099 & 4,436 \\
Honda Fit & 0 & 143 & 59 & 853 & 1,055 \\
Mitsubishi i-Miev & 484 & 274 & 436 & 527 & 1,721 \\
Nissan Leaf & 4,003 & 3,287 & 23,680 & 38,890 & 69,860 \\
Smart EV & 89 & 633 & 379 & 2,976 & 4,077 \\
Tesla S & 3,260 & 4,548 & 8,303 & 22,124 & 38,235 \\
Toyota Rav4 & 19 & 17 & 26 & 2,394 & 2,456 \\
& & & & & \\
Total & 8,269 & 9,252 & 33,633 & 81,140 & 132,294 \\
\hline
\end{tabular}

Panel B: Vehicle Counts by Urban and Rural

\begin{tabular}{lrrrr}
\hline & Nissan: Leaf & Tesla: Model S & Other & Total \\
\hline Urban & 68,292 & 37,596 & 23,828 & 129,716 \\
Rural & 1,568 & 639 & 371 & 2,578 \\
Total & 69,860 & 38,235 & 24,199 & 132,294 \\
\hline
\end{tabular}

Panel C: Vehicle Counts for Top 10 Metropolitan Statistical Areas (MSAs)

\begin{tabular}{lr}
\hline City (MSA) & Number of Vehicles \\
\hline Atlanta, GA & 14,496 \\
Los Angeles, CA & 13,854 \\
San Jose, CA & 11,170 \\
Oakland, CA & 8,131 \\
San Francisco, CA & 6,437 \\
Seattle, WA & 6,352 \\
Santa Ana, CA & 5,734 \\
San Diego, CA & 5,722 \\
Portland, OR & 3,105 \\
Sacramento, CA & 2,838 \\
\hline
\end{tabular}


in which consumers that had just purchased a given electric vehicle were asked to state the vehicle "model most seriously considered" as an alternative. The emissions for the composite gasoline vehicle are defined as the weighted average of the emissions from the 10 most frequently identified gasoline alternatives 10

To calculate the local air pollution damages of a given composite forgone gasoline vehicle driven in county $i$, we use emissions factors per mile to calculate the exhaust emissions of $\mathrm{NO}_{\mathrm{X}}, \mathrm{PM}_{2.5}, \mathrm{SO}_{2}$, and VOCs and non-exhaust emissions of $\mathrm{PM}_{2.5}$ (from tire wear, brake wear, and road wear). We first use the AP2 integrated assessment air pollution model to estimate the dispersion of these pollutants across counties and the formation of secondary $\mathrm{PM}_{2.5}$ and ozone 11 We then use AP2 to calculate the damages from these pollutants due to effects on human health, crop and timber yields, buildings and material, and visibility and recreation that occur in various counties. Aggregating across pollutants yields a single damage value for each county that is affected by driving in county $i$. More formally, let model $m$ denote a particular electric vehicle as well as the corresponding forgone gasoline vehicle. Let $g_{i j}^{m}$ be the damages per year to county $j$ caused by driving a gasoline vehicle $m$ for 15,000 miles in county $i$. The collection of the $g_{i j}^{m}$ into the matrix $G^{m}$ is a useful way to summarize the potential for gasoline model $m$ to generate air pollution damages. We use the word potential because we have not yet accounted for the fact that a given county $i$ may or may not have any model $m$ electric vehicles registered in it.

To calculate the local air pollution damages of an electric vehicle driven in county $i$, we assume that the vehicle is charged in county $i$ and that this increases the electricity load in the electricity region in which the county is located.12 The amount by which load increases per mile depends on both the efficiency of the electric vehicle and the ambient temperature (which affects battery performance). An increase in electricity load in a given region leads to responses by various power plants which in turn changes the emissions from

\footnotetext{
${ }^{10}$ For example, Nissan Leaf purchasers identified the following vehicles (number of responses in parenthesis): Toyota Prius (2166), Kia Soul (344), Ford Fusion (301), Honda Accord (263), Nissan Juke (249), Lexus CT200h (231), Toyota Prius V (227), Audi A5 (201), Nissan Altima (189), Honda CR-V (182). We use the number of responses as weights in the emissions calculations. We did not have any data for the electric Honda Fit and the electric Fiat 500 so we used the gasoline-powered Fit and gasoline-powered Fiat 500 as the forgone gasoline vehicles. For more details, see Section E in the online appendix to Holland et al (2016).

${ }^{11}$ See Muller and Mendelsohn (2009) and Muller (2011) for a description of AP2.

${ }^{12}$ See the Appendix for a map of the nine electricity regions.
} 
these plants. We estimate these effects econometrically. In particular, we determine the relationship for each hour of the day between emissions of $\mathrm{NO}_{\mathrm{X}}, \mathrm{SO}_{2}$, and $\mathrm{PM}_{2.5}$ at each power plant and electricity load in a given electricity region, controlling for load in other regions and month-of-sample fixed effects. The resulting marginal emissions factors show how emissions change at each power plant from charging an electric vehicle in county $i$. The damages from these emissions are then assessed using the AP2 model just as is done for gasoline vehicles. Aggregating across power plants and pollutants yields the local pollution damages to each county $j$ of charging an electric vehicle in county $i$.

In addition to power plant emissions, driving an electric vehicle also causes non-exhaust emissions of $\mathrm{PM}_{2.5}$ due to tire and road wear.13 We combine damages from charging and non-exhaust damages from driving to obtain the damages for the electric vehicle. Let $e_{i j}^{m}$ be the damages per year to county $j$ caused by driving an electric vehicle of model $m$ for 15,000 miles in county $i$. The collection of the $e_{i j}^{m}$ into the matrix $E^{m}$ is a useful way to summarize the potential for electric vehicle model $m$ to generate air pollution damages.

We combine the potential damages described by the matrices $E^{m}$ and $G^{m}$ with the data on registration numbers and location to determine the actual environmental benefits due to the fleet of electric vehicles. We distinguish between received environmental benefits and created environmental benefits. Intuitively, the rows of the matrix of environmental benefits $\left(G^{m}-E^{m}\right)$ are associated with created environmental benefits (driving in county $i$ creates benefits in various counties $j$ ) whereas the the columns are associated with received environmental benefits (driving in the various counties $i$ leads to county $j$ receiving benefits.)

First consider created environmental benefits. Let $n_{i}^{m}$ denote the number of vehicles of model $m$ registered in county $i$. The created environmental benefits in county $i$ from driving this vehicle model are given by the difference between damages created by the forgone gasoline vehicles and damages created by the electric vehicles:

$$
n_{i}^{m} \sum_{j} g_{i j}^{m}-n_{i}^{m} \sum_{j} e_{i j}^{m}=n_{i}^{m} \sum_{j}\left(g_{i j}^{m}-e_{i j}^{m}\right)
$$

\footnotetext{
${ }^{13}$ We assume brake wear is zero for electric vehicles because they use regenerative braking. Heavier vehicles generate more non-exhaust emissions and electric vehicles tend to be heavier than gasoline vehicles due to the weight of the batteries. For both gasoline and electric vehicles, we determine weight-adjusted non-exhaust emissions factors based on data in Table 1 of Timmers and Achten, (2016). Holland et al., (2016) did not account for non-exhaust emissions from electric vehicles.
} 
The expression on the right-hand-side is a multiple of the $i$ 'th row sum of the matrix $\left(G^{m}-E^{m}\right)$. Aggregating over all models $m$ gives the environmental benefits created by county $i$ from driving the entire fleet of vehicles 15,000 miles a year. Next consider received environmental benefits. For a given vehicle model, the environmental benefits received by county $j$ from the driving the fleet of vehicles in their county of registration is the difference between received damages from the gasoline vehicles and received damages from the electric vehicles:

$$
\sum_{i} n_{i}^{m} g_{i j}^{m}-\sum_{i} n_{i}^{m} e_{i j}^{m}=\sum_{i} n_{i}^{m}\left(g_{i j}^{m}-e_{i j}^{m}\right)
$$

Because the number of vehicles in each county is not the same, the environmental benefits received is not simply a multiple of the $j^{\prime}$ th column sum of the matrix $\left(G^{m}-E^{m}\right)$ but rather is a weighted column sum ${ }^{14}$ Aggregating over all models, $m$, gives the environmental benefits received in county $j$ from driving the entire fleet of electric vehicles 15,000 miles in a year.

In our baseline specification, we assume (as in AP2) that damages are evenly distributed across all census block groups in a given county. There is evidence, however, that nearroadway air pollution leads to negative health outcomes (Ghosh et al., 2016, Health Effects Institute 2010, Anderson 2016). There is also evidence that people with low income and nonwhites are disproportionately exposed to traffic density (Rowangould 2013). So one might be concerned that these considerations would influence the distributional effects we want to study in this paper. In the sensitivity analysis, we make a road correction that adjusts for distance that the census block groups are from major highways. We do not include the road correction in our baseline because, among other things, not all pollutants have higher concentrations near roads (Ghosh et al., 2016, Karner et al., 2010, and Anderson 2016).

\subsection{Environmental Benefits Created and Received}

We first analyze created environmental benefits to illustrate the sources of environmental benefits from electric vehicles. Table 2 summarizes the results. Air pollution damages from driving the entire fleet of electric vehicles totals $\$ 25.2$ million per year which slightly exceeds

\footnotetext{
${ }^{14}$ If the number of vehicles in each county were the same, then we could pull $n_{i}^{m}$ out of the sum on the right-hand-side, and the environmental benefits received would be a multiple of the $j$ 'th column sum of the matrix $\left(G^{m}-E^{m}\right)$.
} 
the total damages from a fleet of forgone gasoline vehicles. Thus the total environmental benefit of the fleet of electric vehicles is $-\$ 0.04$ million. Panel A shows the results by vehicle model. The sign of the environmental benefit is largely determined by where the vehicles are driven. For the five models with positive environmental benefits, over $90 \%$ of the vehicles are located in the west. The other vehicles are more uniformly distributed across the country. Panel B disaggregates the environmental benefit by region. The negative environmental benefits are spread throughout three of the four regions, with the largest losses occurring in the South where damages from the electric vehicle fleet were $\$ 5.2$ million more than the damages would have been from driving gasoline vehicles. In the West, the environmental benefits are positive and substantial: $\$ 10.3$ million. This is further illustrated in Panel C which shows the environmental benefits for the top 10 MSAs by vehicle counts. Only one of these MSAs has substantial negative environmental benefits and that MSA, Atlanta, is located in the South. Eight of the nine MSAs in the West have positive environmental benefits with substantial environmental benefits of $\$ 4.6$ million in Los Angeles alone.

The created environmental benefits are disaggregated to the county level and mapped in Figure 1. About half the counties have no created environmental benefits because they have no electric vehicles. The counties where environmental benefits are positive are almost exclusively in the West and primarily in coastal California. Other counties where electric vehicles are creating positive environmental benefits are in major cities in the West: Seattle, Denver, Salt Lake City, and Phoenix. Electric vehicles in much of the rural West create negative environmental benefits as do electric vehicles throughout the East. Note especially the negative created environmental benefits in large cities such as Atlanta and Chicago.

The created environmental benefits show where electric vehicles are producing positive and negative environmental benefits. However to analyze who is affected by these electric vehicles, we must analyze the received environmental benefits, because wind and the electricity grid disperse pollution far beyond the location of the electric vehicle. Figure 2 maps the received environmental benefits for each county.

There are several interesting differences between the maps in Figure 2 and Figure 1. First, the positive environmental benefits received are spread much more widely across the West. For example, inland counties in California and Nevada had few or no electric vehicles and 
Table 2: Gasoline Damages, Electric Damages and Environmental Benefits Created (\$ 1000 's)

Panel A: By vehicle

\begin{tabular}{lrrr}
\hline Type & $\begin{array}{r}\text { Gasoline } \\
\text { Vehicle }\end{array}$ & $\begin{array}{r}\text { Electric } \\
\text { Vehicle }\end{array}$ & $\begin{array}{r}\text { Enviro } \\
\text { Benefit }\end{array}$ \\
\hline Chevy Spark & 425 & 160 & 266 \\
Fiat 500 & 2,165 & 689 & 1,477 \\
Ford Focus & 741 & 767 & -27 \\
Honda Fit & 255 & 142 & 113 \\
Mitsubishi i-Miev & 214 & 454 & -240 \\
Nissan Leaf & 10,903 & 12,935 & $-2,032$ \\
Smart EV & 794 & 563 & 231 \\
Tesla S & 9,007 & 9,170 & -163 \\
Toyota Rav4 & 625 & 293 & 332 \\
Total & 25,129 & 25,173 & -44 \\
\hline
\end{tabular}

Panel B: By Region

\begin{tabular}{lrrr}
\hline Type & $\begin{array}{r}\text { Gasoline } \\
\text { Vehicle }\end{array}$ & $\begin{array}{r}\text { Electric } \\
\text { Vehicle }\end{array}$ & $\begin{array}{r}\text { Enviro } \\
\text { Benefit }\end{array}$ \\
\hline Midwest & 1,338 & 4,047 & $-2,709$ \\
Northeast & 1,538 & 3,975 & $-2,437$ \\
South & 4,778 & 9,952 & $-5,174$ \\
West & 17,475 & 7,198 & 10,276 \\
Total & 25,129 & 25,173 & -44 \\
\hline
\end{tabular}

Panel C: Top 10 MSAs by Electric Vehicle Counts

\begin{tabular}{lrrr}
\hline & Gasoline & Electric & Enviro \\
Type & Vehicle & Vehicle & Benefit \\
\hline Atlanta, GA & 2,894 & 4,926 & $-2,032$ \\
Los Angeles, CA & 6,182 & 1,567 & 4,615 \\
San Jose, CA & 3,042 & 1,395 & 1,647 \\
Oakland, CA & 2,219 & 978 & 1,241 \\
San Francisco, CA & 1,469 & 672 & 797 \\
Seattle, WA & 541 & 444 & 97 \\
Santa Ana, CA & 1,269 & 359 & 910 \\
San Diego, CA & 1,157 & 493 & 664 \\
Portland, OR & 134 & 168 & -34 \\
Sacramento, CA & 234 & 122 & 112 \\
\hline
\end{tabular}


Figure 1: Environmental Benefits Created by County $(\$ 1,000)$

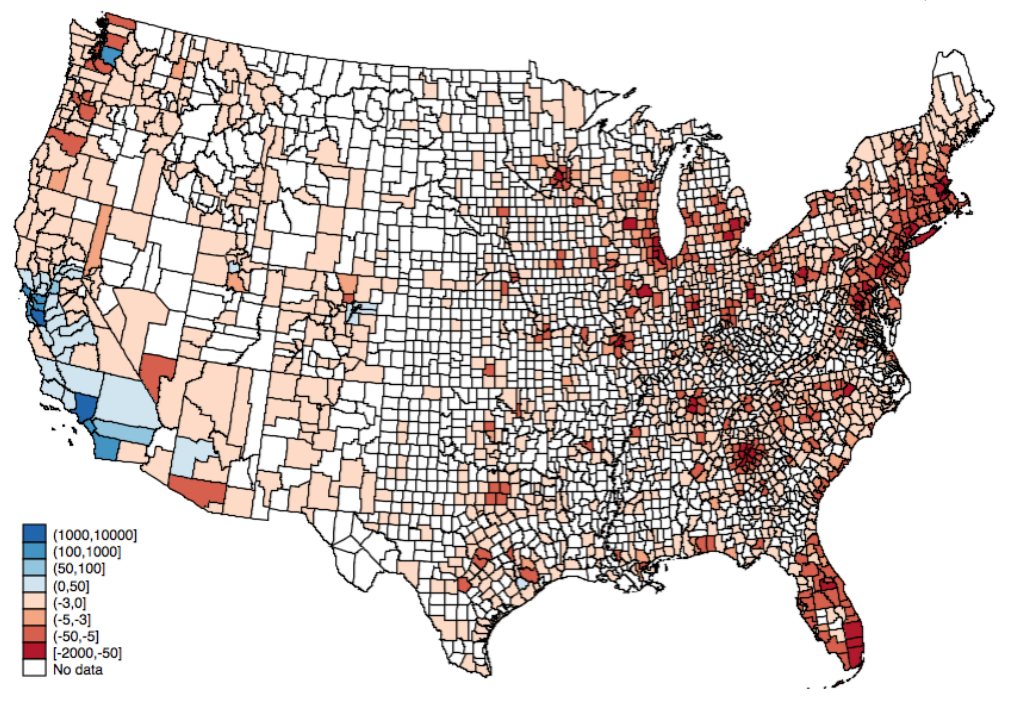

Figure 2: Environmental Benefits Received by County $(\$ 1,000)$

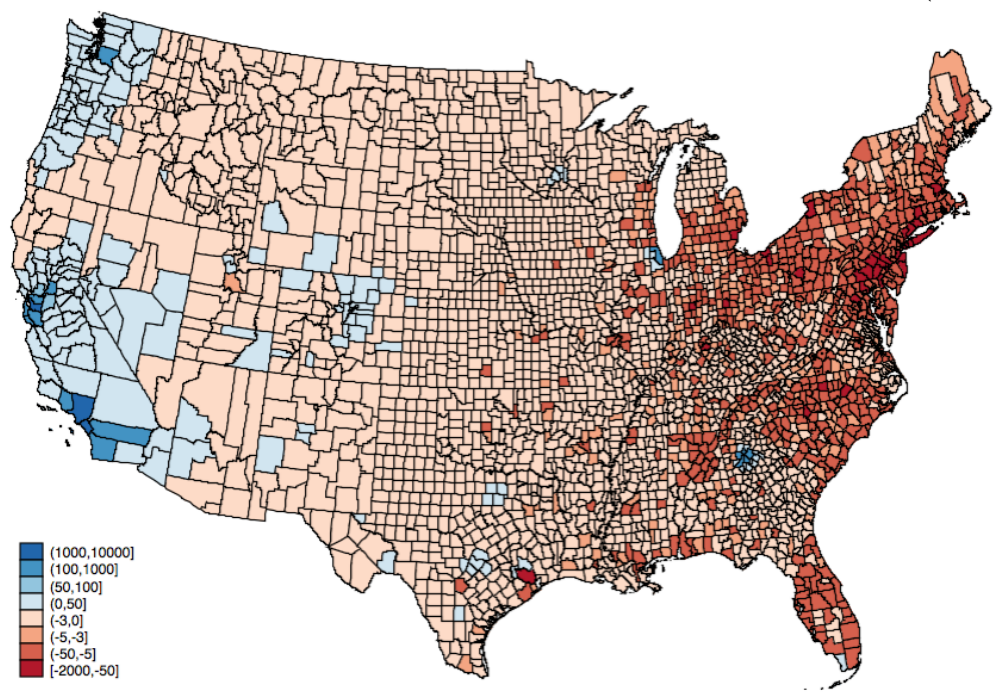


thus created negligible environmental benefits. However, these counties still suffered harm from gasoline vehicles driven in coastal California and thus receive environmental benefits from the fleet of electric vehicles, many of which were located in coastal California.

Second, many urban counties in the East receive positive environmental benefits from the fleet of electric vehicles, despite the fact that electric vehicles throughout the East create negative environmental benefits. For example, the electric vehicles in Fulton County, Georgia in Atlanta create negative environmental benefits. However Fulton County receives positive environmental benefits from the electric vehicle fleet, many of which are located in Atlanta. In effect, the electric vehicles in Atlanta export pollution to other counties making Atlanta better off despite creating negative environmental benefits overall. Finally, many counties in the Pacific Northwest receive positive environmental benefits despite creating negligible or negative environmental benefits. This is because of the export of negative environmental benefits from these coastal counties to the rural areas inland.

Table 3 aggregates the received environmental benefits to different levels. The contrast between benefits created and received is, generally, a decreasing function of modeling aggregation. Within the entire national accounting domain the two measures of benefits must equate. Similarly, the aggregation by census region in Panel A of Table 3 for received environmental benefits is quite similar to that in in Panel B of Table 2 for created environmental benefits. Different levels of aggregation show sharper contrast. Panel B of Table 3 shows the distribution across urban and rural counties. Rural counties receive a much higher proportion of damages from electric vehicles than from the forgone gasoline vehicles and thus receive most of the negative environmental benefit from electric vehicles. The distribution across MSAs (Panel C) also has some notable differences between received and created environmental benefits. First, the Atlanta MSA received positive environmental benefits despite creating negative environmental benefits. This is because the negative created environmental benefits are exported to counties not in the Atlanta MSA. Second, the environmental benefits received by the California cities are generally smaller than the benefits created. In this case the positive created environmental benefits are exported to counties outside the MSA so the received environmental benefits are smaller than the created benefits. The maps in Figures 1 and 2 provide the least aggregated comparison, and hence show the most contrast. 
Table 3: Gasoline Damages, Electric Damages and Environmental Benefits Received (\$ 1000 's)

Panel A: By Region

\begin{tabular}{lrrr}
\hline Type & $\begin{array}{r}\text { Gasoline } \\
\text { Vehicle }\end{array}$ & $\begin{array}{r}\text { Electric } \\
\text { Vehicle }\end{array}$ & $\begin{array}{r}\text { Enviro } \\
\text { Benefit }\end{array}$ \\
\hline Midwest & 1,378 & 3,707 & $-2,329$ \\
Northeast & 1,616 & 5,699 & $-4,083$ \\
South & 4,731 & 8,909 & $-4,178$ \\
West & 17,404 & 6,858 & 10,545 \\
Total & 25,129 & 25,173 & -44 \\
\hline
\end{tabular}

Panel B: By urban

\begin{tabular}{lrrr}
\hline & Gasoline & Electric & Enviro \\
Type & Vehicle & Vehicle & Benefit \\
\hline Urban & 24,704 & 21,770 & 2,934 \\
Rural & 425 & 3,403 & $-2,978$ \\
Total & 25,129 & 25,173 & -44 \\
\hline
\end{tabular}

Panel $C$ : By MSAs

\begin{tabular}{lrrr}
\hline & Gasoline & Electric & Enviro \\
Type & Vehicle & Vehicle & Benefit \\
\hline Atlanta, GA & 2,649 & 1,412 & 1,237 \\
Los Angeles, CA & 5,332 & 1,950 & 3,382 \\
San Jose, CA & 1,536 & 595 & 941 \\
Oakland, CA & 2,769 & 1,196 & 1,573 \\
San Francisco, CA & 1,763 & 752 & 1,012 \\
Seattle, WA & 492 & 155 & 336 \\
Santa Ana, CA & 1,817 & 430 & 1,387 \\
San Diego, CA & 1,139 & 462 & 677 \\
Portland, OR & 123 & 41 & 82 \\
Sacramento, CA & 260 & 122 & 138 \\
\hline
\end{tabular}


This distinction between benefits created and received can lead to stark policy differences. For example, created benefits from electric vehicle use in Atlanta, Georgia are estimated to be $-\$ 2.0$ million. Benefits received are $\$ 1.2$ million. Thus, the sign changes depending on whether one considers Atlanta as a source of emissions or as a receptor of emissions. There are important policy implications revealed by this result. If policymakers in Atlanta ask whether or not to subsidize electric vehicles, the answer depends on jurisdiction and both the distribution of created and received benefits. That is, Atlanta regulators may favor a policy that encourages electric vehicle adoption in locations upwind from, and including, Atlanta. Benefits received are positive. Conversely, federal policymakers may frown upon subsidizing electric vehicle use in Atlanta itself because benefits created are negative. Thus the connection between analyzing created versus received benefits and policy design.

The difference between created and received environmental benefits is also related to native damages as defined by Holland et al., (2016) ${ }^{15}$ Both concepts quantify the flow of pollution across jurisdictional boundaries due to wind patterns and the electricity grid. However, native damages are based on driving a vehicle at a specific location and received damages are based on driving by the entire fleet of electric vehicles. The basic lesson remains the same: the environmental benefits of electric vehicles can seem larger if only nearby damages are considered.

\section{Equity: Whose Air Quality Is Affected by Driving Electric Vehicles?}

We now analyze the distribution of the received environmental benefits across demographic groups. We first illustrate the distribution of received environmental benefits with summary statistics and graphical analyses. We then present econometric analysis of the demographic correlates of the received environmental benefits.

Our calculated environmental benefits are at the county level. However, county level data mask significant variation in demographics. Thus, we collect demographic data at the

\footnotetext{
${ }^{15}$ Native damages are the damages from driving an electric vehicle in a county (or state) which affect people in that county (or state).
} 
census block group level and use that to create per capita damages received from gasoline and electric vehicles and per capita environmental benefits received. Table 4 shows summary statistics of the per capita damages, environmental benefits, and demographic variables ${ }^{16}$ The average person received $\$ 0.08$ per year in air pollution damages from the fleet of electric vehicles and would have received similar damages from the forgone gasoline vehicle fleet, yielding essentially zero environmental benefit. However, this average masks significant heterogeneity: received environmental benefits range from $-\$ 0.30$ to $\$ 0.81$ per capita.

Table 4: Received Benefits per Capita and Demographic Variables

\begin{tabular}{lcccc}
\hline Variable & Mean & Std. Dev. & Min & Max \\
\hline Gas vehicle damages p.c. & 0.081 & 0.19 & 0.001 & 1.335 \\
Elec vehicle damages p.c. & 0.081 & 0.075 & -0.002 & 0.546 \\
EV net benefits p.c. & 0 & 0.139 & -0.297 & 0.813 \\
Income (10k) & 6 & 3.143 & 0.25 & 25 \\
Share Black & 0.126 & 0.217 & 0 & 1 \\
Share Hispanic & 0.161 & 0.229 & 0 & 1 \\
Share Asian & 0.046 & 0.093 & 0 & 1 \\
Share White & 0.643 & 0.311 & 0 & 1 \\
Urban Indicator & 0.836 & 0.37 & 0 & 1 \\
Share Poverty & 0.136 & 0.129 & 0 & 1 \\
\hline
\end{tabular}

Notes: Block groups are weighted by population. There are 215,328 block groups with a total population of 305 million. "p.c." is per capita. Damages and environmental benefits are received environmental benefits.

We next analyze inequality in the distribution of these per capita benefits using the familiar concepts of Lorenz curves and Gini coefficients. These measures are most commonly used to described inequality in the distribution of income, but can be used to describe inequality in the distribution of any single variable. The Lorenz curve gives a visual measure of inequality and the Gini coefficient gives a numerical measure of inequality. A higher Gini coefficient, which ranges from zero to one and is calculated from the Lorenz curve, indicates more inequality. Figure 3 illustrates the distribution of per capita received damages using Lorenz curves and compares them to the Lorenz curve for income. To graph the Lorenz curve for income in Figure 3, we first rank individuals by their income 17 We then graph the cumulative fraction of the population on the horizontal axis and the cumulative fraction of the income received by these individuals on the vertical axis. For example, the Lorenz

\footnotetext{
${ }^{16}$ Income is measured by median household income at the block group level. Average income is $\$ 60,000$ (the overall median income in the U.S. is $\$ 53,000$ ).

${ }^{17}$ Technically, we rank block groups and then weight by population.
} 
curve shows that the poorest $60 \%$ of people receive $40 \%$ of the total income. Also drawn is the 45-degree line. The further the Lorenz curve is from the 45-degree line, the greater the inequality of the distribution of income, and the higher is the Gini coefficient.

We follow a similar procedure to graph the Lorenz curve for received electric vehicle damages per capita in Figure 3. We first rank individuals by their received electric vehicle damages per capita. We then graph the cumulative fraction (by electric vehicle damages) of the population on the horizontal axis and the cumulative fraction of the electric vehicle damages received by these individuals on the vertical axis. The Lorenz curve shows, for example, that the $60 \%$ of people who receive the least electric vehicle damages, receive approximately $30 \%$ of the total electric vehicles damages. Similarly, we can graph the Lorenz curve for forgone gasoline vehicle damages. This graph shows that the $60 \%$ of people who receive the least gasoline vehicle damages, receive only about $10 \%$ of the total gasoline vehicle damages.

Comparing the three Lorenz curves in Figure 3 with the 45-degree line allows us to assess the relative concentration of income and damages from electric and forgone gasoline vehicles. Compared to the distribution of income, which is itself relatively concentrated (Gini $=0.275){ }^{18}$ damages from both gasoline and electric vehicles are more concentrated, i.e., the bulk of the damages are concentrated among a relatively small set of individuals. Comparing the gasoline damages $(\mathrm{Gini}=0.768)$ and electric vehicle damages $(\mathrm{Gini}=0.429)$ shows that the damages from gasoline vehicles are much more concentrated. Moving from the fleet of these forgone gasoline vehicles to the corresponding fleet of electric vehicles significantly lowers the concentration of damages. In this sense, electric vehicles are more egalitarian than gasoline vehicles.

Lorenz curves are useful for analyzing the distribution of a single variable but do not shed much light on the relationship between variables. For example, the Lorenz curve cannot tell us whether or not the individuals receiving a large share of the damages from electric vehicles are also receiving a large share of damages from forgone gasoline vehicles. In addition, we would like to know whether those individuals receiving environmental benefits from electric

\footnotetext{
${ }^{18}$ For the year 2013, The World Bank reports a Gini coefficient for the U.S. of approximately 0.4. Our calculated Gini coefficient is lower because it is based on median block-group income rather than more disaggregated household data.
} 
Figure 3: Lorenz Curves: Income and Air Pollution Damages from Driving

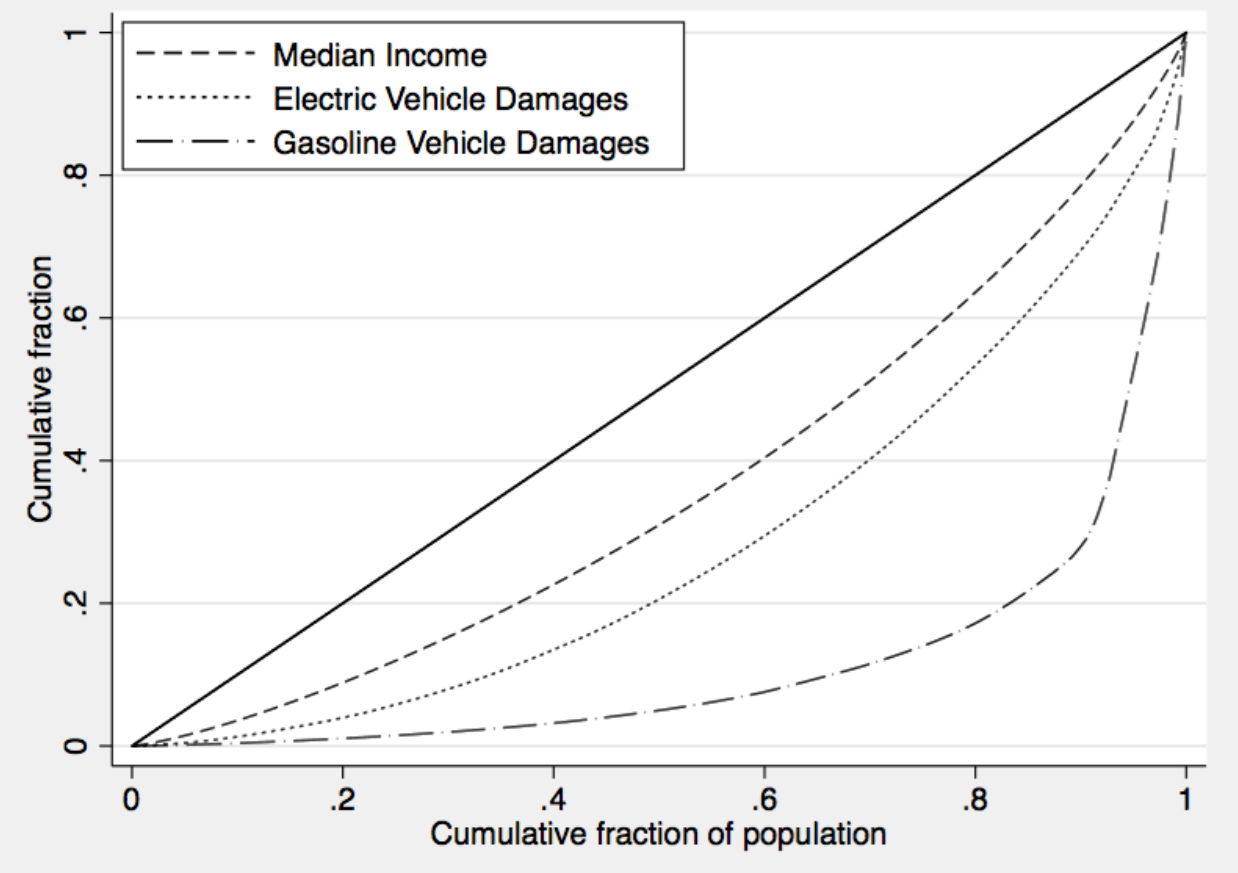

Notes: The horizontal axis is the cumulative fraction of individuals ranked by income, electric vehicle damages or gasoline vehicle damages. The vertical axis is the cumulative fraction of the relevant variable (income, electric vehicle damages, gasoline vehicle damages).

vehicles are relatively rich or poor.

To answer these questions, we turn to multivariate analyses. We begin by exploring the relationship between income and damages. Figure 4 shows graphs of smoothed values with 95\% confidence bands from kernel-weighted local polynomial regressions of damages per capita on houshold income. Received damages per capita from forgone gasoline vehicles are higher on average for households with higher income. In contrast, damages received from electric vehicles are relatively constant in income 19 The difference between damages from forgone gasoline vehicles and electric vehicles is the environmental benefit of electric vehicles. The environmental benefits are positive for block groups with household income greater than about $\$ 65,000$, but negative below this level. Thus individuals with income above this level receive a positive environmental benefit from electric vehicles on average, but individuals with income below this receive a negative environmental benefit on average. Because the overall environmental benefit is slightly negative, the gains to the rich individuals

\footnotetext{
${ }^{19}$ This result, in conjunction with the Lorenz curves for damages, suggests that the abbreviation EV for electric vehicles may well also stand for "egalitarian vehicles".
} 
are outweighed by the losses to the poor individuals. 20

Figure 4: Air Pollution Damages Received and Income

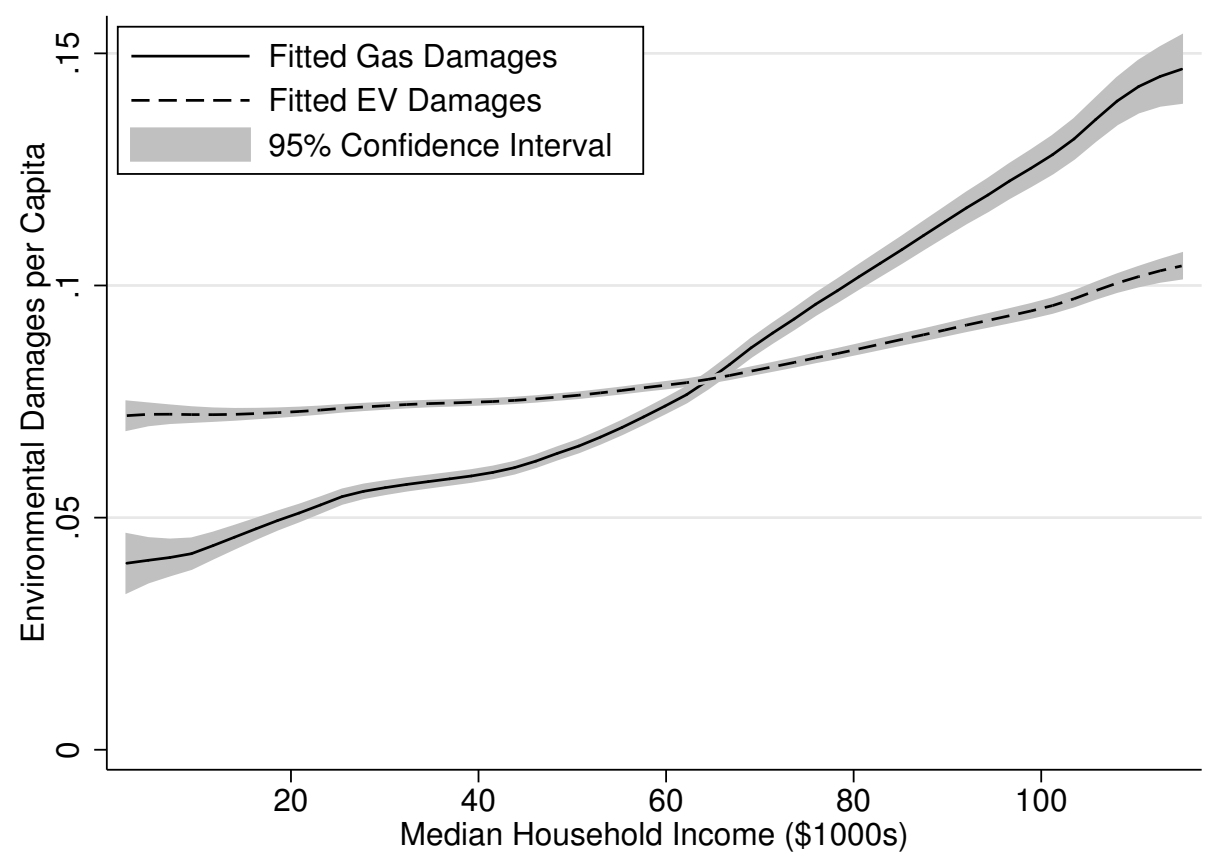

Notes: For gasoline and electric vehicles, the figure shows a kernel-weighted local-mean smoothing regression of per capita damages of driving on a block group's median household income using an Epanechnikov kernel function with a half-width of $\$ 5,000$.

Figure 4 shows a strong correlation between income and environmental benefit. Table 5 breaks out the environmental benefit by both income and racial groups. We first identify the income decile of each block group. The column labeled "All" reports population-weighted averages of the environmental benefits per capita across the block groups for each income decile ${ }^{21}$ The columns show that the environmental benefit per capita is increasing across the income deciles. In particular, the environmental benefit is negative for the six poorest deciles and is only positive for the richest four deciles.22

The bottom row of Table 5 breaks out the environmental benefit by race. This row re-

\footnotetext{
${ }^{20}$ Cumulative distributions as a function of income are given in the Appendix.

${ }^{21}$ More specifically, for each block group in decile $x$ we multiply the environmental benefit per capita by the population in the block group. We then sum this product over all block groups in decile $x$ and divide by the population in all block groups in decile $x$.

${ }^{22}$ This is consistent with the evidence in Figure 4. In Figure 4, benefits go from negative to positive at $\$ 65,000$ which is the 65 th percentile of income.
} 
ports popultation-weighted averages of the environmental benefits per capita for each racial category ${ }^{23}$ The results show differential effects across racial groups: White and Black populations are harmed on average by electric vehicles, but Asian and Hispanic populations benefit on average.

The remainder of the table breaks out environmental benefit by income and race. Each cell reports the population-weighted average of the environmental benefits per capita across the block groups for each income decile ${ }^{24}$ There is remarkable consistency across both dimensions. For each income decile, Hispanic and Asian populations receive higher environmental benefit per capita than White and Black populations. Similarly for each racial group, individuals in higher income decile block groups receive higher environmental benefits than individuals in lower income decile block groups. The crossover points at which environmental benefits become positive are also noteworthy. White populations have an environmental benefit per capita which is lower than average and the crossover point is higher (in the eighth decile). Black populations have an environmental benefit which is higher than average and has a crossover point which is lower (in the sixth decile). Both Hispanic and Asian populations benefit across all the income deciles.

We next turn to descriptive regressions showing correlations between environmental benefits per capita and our demographic variables in Tables 6, 7, and 8. The results in Table 5 suggest certain relationships, but regressions allow us to assess the statistical significance of these correlations.

We begin in Table 6 with univariate regressions showing the simple correlations. Individuals with higher incomes have slightly higher environmental benefits: an extra $\$ 10,000$ in income is associated with an $\$ 0.007$ increase in benefits. Our urban measures (population density and an urban indicator) are each positively correlated with benefits. Our racial variables are strongly correlated with environmental benefits consistent with the results in Table 5. The share of Black and White residents are negatively correlated with benefits but

\footnotetext{
${ }^{23}$ For example for the variable labelled Black, for each block group we multiply the environmental benefit per capita by the black population in the block group. We then sum this product over all block groups and divide by the total black population.

${ }^{24}$ More specifically, for each block group in decile $x$ we multiply the environmental benefit per capita by the population of that racial group in the block group. We then sum this product over all block groups in decile $x$ and divide by the population of that racial group in all block groups in decile $x$.
} 
Table 5: Environmental Benefits per Capita of Electric Vehicles by Race and Income

\begin{tabular}{crrrrr}
\hline & \multicolumn{5}{c}{ Demographic Group } \\
Income Decile & Black & Hispanic & Asian & White & All \\
\hline 1 & -0.032 & 0.019 & 0.064 & -0.047 & -0.023 \\
2 & -0.021 & 0.043 & 0.069 & -0.045 & -0.016 \\
3 & -0.020 & 0.051 & 0.071 & -0.044 & -0.018 \\
4 & -0.009 & 0.057 & 0.081 & -0.040 & -0.014 \\
5 & -0.007 & 0.063 & 0.091 & -0.035 & -0.011 \\
6 & -0.001 & 0.068 & 0.101 & -0.031 & -0.007 \\
7 & 0.007 & 0.076 & 0.107 & -0.022 & 0.001 \\
8 & 0.011 & 0.084 & 0.133 & -0.011 & 0.012 \\
9 & 0.011 & 0.094 & 0.138 & 0.003 & 0.025 \\
10 & 0.016 & 0.097 & 0.164 & 0.032 & 0.050 \\
& & & & & \\
Total & -0.013 & 0.058 & 0.116 & -0.021 & -0.000 \\
\hline
\end{tabular}

Notes: Environmental benefits of all electric vehicles driving 15,000 in a year by race and income deciles.

Table 6: Correlates of Environmental Benefits Received per Capita

\begin{tabular}{|c|c|c|c|c|c|c|c|c|}
\hline & $(1)$ & $(2)$ & $(3)$ & $(4)$ & $(5)$ & $(6)$ & $(7)$ & $(8)$ \\
\hline Income (10k) & $\begin{array}{c}0.007^{* * *} \\
(0.002)\end{array}$ & & & & & & & \\
\hline Share Poverty & & $\begin{array}{l}-0.035 \\
(0.024)\end{array}$ & & & & & & \\
\hline Urban Indicator & & & $\begin{array}{c}0.071^{* * * *} \\
(0.016)\end{array}$ & & & & & \\
\hline Population Density & & & & $\begin{array}{l}0.002^{*} \\
(0.001)\end{array}$ & & & & \\
\hline Share Black & & & & & $\begin{array}{c}-0.034 \\
(0.021)\end{array}$ & & & \\
\hline Share Hispanic & & & & & & $\begin{array}{c}0.179 * * * \\
(0.051)\end{array}$ & & \\
\hline Share Asian & & & & & & & $\begin{array}{c}0.616^{* * *} \\
(0.118)\end{array}$ & \\
\hline Share White & & & & & & & & $\begin{array}{c}-0.140^{* * *} \\
(0.038)\end{array}$ \\
\hline
\end{tabular}

Notes: Dependent variable is environmental benefit per capita. WLS regressions weight by total population and cluster standard errors by county. 
Table 7: Descriptive Regressions of Environmental Benefits Received per Capita

\begin{tabular}{|c|c|c|c|c|c|c|c|c|}
\hline & (1) & $(2)$ & $(3)$ & $(4)$ & $(5)$ & $(6)$ & $(7)$ & $(8)$ \\
\hline Income (10k) & $\begin{array}{c}0.007^{* * *} \\
(0.002)\end{array}$ & $\begin{array}{c}0.005^{* * *} \\
(0.002)\end{array}$ & $\begin{array}{c}0.010^{* * *} \\
(0.002)\end{array}$ & $\begin{array}{c}0.009^{* * *} \\
(0.002)\end{array}$ & $\begin{array}{l}0.003^{* *} \\
(0.001)\end{array}$ & $\begin{array}{c}0.002 \\
(0.001)\end{array}$ & $\begin{array}{c}0.011^{* * *} \\
(0.003)\end{array}$ & $\begin{array}{c}0.011^{* * *} \\
(0.003)\end{array}$ \\
\hline Urban Indicator & & $\begin{array}{c}0.064^{* * *} \\
(0.016)\end{array}$ & & $\begin{array}{c}0.034^{* * *} \\
(0.007)\end{array}$ & & $\begin{array}{c}0.041^{* * *} \\
(0.011)\end{array}$ & & $\begin{array}{c}0.019^{* * *} \\
(0.005)\end{array}$ \\
\hline Share Black & $\begin{array}{l}-0.009 \\
(0.019)\end{array}$ & $\begin{array}{l}-0.025 \\
(0.021)\end{array}$ & & & & & & \\
\hline Share Hispanic & & & $\begin{array}{c}0.206^{* * *} \\
(0.055)\end{array}$ & $\begin{array}{c}0.194^{* * *} \\
(0.053)\end{array}$ & & & & \\
\hline Share Asian & & & & & $\begin{array}{c}0.595^{* * *} \\
(0.116)\end{array}$ & $\begin{array}{c}0.572^{* * *} \\
(0.115)\end{array}$ & & \\
\hline Share White & & & & & & & $\begin{array}{c}-0.171^{* * *} \\
(0.042)\end{array}$ & $\begin{array}{c}-0.164^{* * *} \\
(0.042)\end{array}$ \\
\hline
\end{tabular}

Notes: Dependent variable is environmental benefit per capita. WLS regressions weight by total population and cluster standard errors by county.

Table 8: Descriptive Regressions of Environmental Benefits Received per Capita

\begin{tabular}{|c|c|c|c|c|c|c|}
\hline & (1) & $(2)$ & (3) & $(4)$ & (5) & $(6)$ \\
\hline Income (10k) & $\begin{array}{c}0.006^{* * *} \\
(0.002)\end{array}$ & $\begin{array}{c}0.004^{* * *} \\
(0.001)\end{array}$ & $\begin{array}{c}0.009^{* * * *} \\
(0.002)\end{array}$ & $\begin{array}{c}0.006^{* * *} \\
(0.001)\end{array}$ & $\begin{array}{c}0.006^{* * *} \\
(0.002)\end{array}$ & $\begin{array}{c}0.004^{* * *} \\
(0.001)\end{array}$ \\
\hline Share Poverty & $\begin{array}{c}-0.017 \\
(0.013)\end{array}$ & $\begin{array}{c}-0.013^{*} \\
(0.007)\end{array}$ & $\begin{array}{c}-0.064^{* * *} \\
(0.020)\end{array}$ & $\begin{array}{c}-0.022^{* * *} \\
(0.008)\end{array}$ & & \\
\hline Urban Indicator & $\begin{array}{c}0.014^{* * *} \\
(0.004)\end{array}$ & $\begin{array}{c}0.013^{* * *} \\
(0.003)\end{array}$ & $\begin{array}{c}0.016^{* * *} \\
(0.005)\end{array}$ & $\begin{array}{c}0.014^{* * *} \\
(0.003)\end{array}$ & $\begin{array}{c}0.014^{* * *} \\
(0.004)\end{array}$ & $\begin{array}{c}0.017^{* * *} \\
(0.003)\end{array}$ \\
\hline Population Density & $\begin{array}{l}-0.000 \\
(0.001)\end{array}$ & $\begin{array}{c}0.001^{* * *} \\
(0.000)\end{array}$ & $\begin{array}{c}0.001 \\
(0.001)\end{array}$ & $\begin{array}{c}0.001^{* * *} \\
(0.000)\end{array}$ & & \\
\hline Share Black & $\begin{array}{c}0.028 \\
(0.017)\end{array}$ & $\begin{array}{c}0.042^{* * *} \\
(0.009)\end{array}$ & & & $\begin{array}{c}0.023 \\
(0.017)\end{array}$ & $\begin{array}{c}0.050^{* * *} \\
(0.009)\end{array}$ \\
\hline Share Hispanic & $\begin{array}{c}0.191^{* * *} \\
(0.048)\end{array}$ & $\begin{array}{c}0.017 \\
(0.015)\end{array}$ & & & $\begin{array}{c}0.186^{* * *} \\
(0.050)\end{array}$ & $\begin{array}{c}0.034^{* *} \\
(0.015)\end{array}$ \\
\hline Share Asian & $\begin{array}{c}0.559^{* * *} \\
(0.103)\end{array}$ & $\begin{array}{c}0.241^{* * *} \\
(0.055)\end{array}$ & & & $\begin{array}{c}0.551^{* * *} \\
(0.111)\end{array}$ & $\begin{array}{c}0.271^{* * *} \\
(0.057)\end{array}$ \\
\hline Share White & & & $\begin{array}{c}-0.163^{* * *} \\
(0.038)\end{array}$ & $\begin{array}{c}-0.048^{* * *} \\
(0.008)\end{array}$ & & \\
\hline State FE & No & Yes & No & Yes & No & Yes \\
\hline
\end{tabular}

Notes: Dependent variable is environmental benefit per capita. WLS regressions weight by total population and cluster standard errors by county. 
the share of Asian and Hispanic residents are positively correlated with benefits.

Table 7 conditions the racial variables on income and the urban indicator. The racial variables are quite robust to these controls. The share of Hispanic and Asian residents still predict positive environmental benefits and share of White residents still predicts negative environmental benefits. Share of Black residents still predicts negative environmental benefits but is not statistically significant. Table 7 can alternatively be interpreted as conditioning the income and urban variables on the racial controls. Both correlations are quite robust to these controls: both signs and significance are the same across the regressions 25

Table 8 tests for correlations conditioning on the entire set of variables. Model (1) includes the entire set of covariates (excluding Share White, which is collinear with the other shares) and model (2) includes state fixed effects. Models (3) and (4) test robustness to the more parsimonious racial categorization, and models (5) and (6) use more parsimonious income and urban variables. In general, the income, urban, and race category predictors are quite robust to the various specifications. Income is quite a robust predictor even in specifications including state fixed effects, and share poverty has additional predictive power in some specifications. In general, our results show that richer people receive greater environmental benefits from electric cars. The urban indicator and population density are highly correlated (correlation coefficient $=0.4)$ and do not have significant independent predictive power in our regressions. However, the combined urban effect is robust even when including state fixed effects. Share of Asian residents has the largest and most robust predictive power of the racial variables. Share of Hispanic residents also predicts higher environmental benefits, and share of White residents predicts lower environmental benefits, although neither of these results are robust to state fixed effects. Share of Black residents is negatively correlated with environmental benefits but is not a significant predictor.

In summary, our evidence shows a strong, robust positive correlation between environmental benefits and our income and urban measures. In addition, Hispanic and Asian shares are positively correlated with environmental benefits, but White share is negatively correlated. Black share is not robustly correlated with environmental benefits of electric vehicles.

\footnotetext{
${ }^{25}$ In addition, the results are robust to splitting the sample into two regions. See the Appendix.
} 


\subsection{Sensitivity: MSA driving, Non-exhaust emissions, Road Cor- rection, and Forgone Vehicles}

We now conduct a sensitivity analysis for some of the assumptions made in the baseline analysis. As discussed above, there is evidence that the effects of air pollution may be concentrated around roads. But, according to Gosh et al., (2016), "the specific pollutants in near-roadway air pollution responsible for health effects are not entirely clear." With this caveat in mind, we conduct a near-roadway sensitivity analysis for the local pollutants in our study. We identify a set of census block groups in a given county such that, for each block group in the set, the centroid of the block group is within 570 meters of a major roadway ${ }^{26}$ We apportion own county exhaust and non-exhaust emissions from forgone gasoline vehicles and own county non-exhaust emissions from electric vehicles across these census block groups in the set according to the inverse distance from the roadway ${ }^{27}$ The results are shown in the column labeled "Road" in Table 9. The total at the bottom of the column is the same as in baseline because we are simply re-apportioning benefits across block groups. Overall, the distribution of environmental benefits becomes more equal across incomes. The biggest changes are an improvement in the lowest income decile (smaller negative environmental benefit) and degradation in the highest income decile (smaller positive environmental benefits). In addition the environmental benefit is no longer increasing in income across the bottom three income deciles.

We also conduct a sensitivity analysis of our assumption that all vehicles are driven exclusively in the county of registration. Here we assume a vehicle that is registered in a county within an MSA is driven in each county in the MSA based on the fraction of the MSA's Vehicle Miles Travelled (VMT) which occurs in each county. For rural vehicles (those registered in a county not in an MSA), we assume that they are driven in each rural county in the state based on the VMT share of the rural county. County-level VMT is from the EPA as estimated for their Motor Vehicle Emission Simulator (MOVES). The results are shown in the column labelled "MSA" in Table 9. Here the total becomes more negative relative to

\footnotetext{
${ }^{26}$ Kaner et al., (2010) show that most pollutants are at background level after the threshold of 570 meters from a highway.

${ }^{27}$ We round up all distances less than 50 meters to be equal to 50 meters.
} 
baseline and environmental benefits decrease for each income decile.

The next sensitivity analysis concerns an additional type of non-exhaust emissions that was not previously considered in our analysis. There is evidence that vehicles driving on roadways re-suspend $\mathrm{PM}_{2.5}$ particles and this effect is stronger for heavier vehicles (Timmers and Achten 2016, Amato et al., 2012). Electric vehicles tend to be heavier on average than gasoline vehicles due to the weight of the batteries. We use data in Table 6 in Timmers and Achten 2016 to determine re-suspended $\mathrm{PM}_{2.5}$ emissions for a forgone gasoline vehicle of average weight, and then determine weight-adjusted emissions for each gasoline and electric vehicle assuming a linear relationship between weight and re-suspension of $\mathrm{PM}_{2.5}$. The results are shown in the column labelled " $\mathrm{PM}_{2.5}$ " in Table 9. Again the total is more negative and environmental benefits decrease for each income decile, to a greater degree than for the MSA analysis.

The final sensitivity analyses consider alternative methods for selecting the forgone gasoline vehicle. First, rather than using a composite vehicle based on consumer preferences as in the baseline analysis, we select one forgone gasoline vehicle for a given electric vehicle. Our choice represents an "engineering" substitute, in the sense that wherever possible, we selected the equivalent gasoline version of the electric vehicle. For example, the forgone gasoline vehicle for the Ford Focus electric vehicle is simply the gasoline powered Ford Focus ${ }^{28}$ The results are shown in the column labelled "Subst" in Table 9. The effects are quite similar to the non-exhaust emissions case. Next we use one forgone gasoline vehicle for all electric vehicles. This forgone vehicle is either the cleanest (the Toyota Prius) or one of the dirtiest (the Mercedes S550) from the entire list of forgone gasoline alternatives identified by the consumer survey data. The results are shown in the columns labelled "Prius" and "Mercedes". Although using the Mercedes as the forgone vehicle implies that the total benefits from electric vehicle adoption are positive, there is still a small negative effect on the lowest income deciles. Similarly, the Prius still leads to positive benefits for the highest income deciles. Therefore our finding that electric vehicles generate negative benefits to low incomes

\footnotetext{
${ }^{28}$ The forgone gasoline vehicle for the Spark, Fiat 500, Ford Focus, Toyota RAV 4, and Smart fortwo are the gasoline version of these vehicles. The forgone vehicle for the Mitsubishi i-Miev is the gasoline Spark, the forgone vehicle for the Nissan Leaf is the Toyota Prius, and the forgone vehicle for the Tesla Model is the BMW 750i.
} 
and positive benefits for high incomes continues to hold, even under extreme assumptions about forgone vehicles.

Table 9: Sensitivity Analysis: Environmental Benefits Per Capita By Income

\begin{tabular}{crrrrrrr}
\hline & & & & & \multicolumn{3}{c}{ Forgone Vehicle } \\
\cline { 6 - 8 } Income Decile & Baseline & MSA & $\mathrm{PM}_{2.5}$ & Road & Subst & Prius & Mercedes \\
\hline 1 & -0.023 & -0.023 & -0.024 & -0.006 & -0.024 & -0.032 & -0.009 \\
2 & -0.016 & -0.017 & -0.018 & -0.006 & -0.018 & -0.027 & -0.000 \\
3 & -0.018 & -0.018 & -0.020 & -0.016 & -0.020 & -0.028 & -0.002 \\
4 & -0.014 & -0.015 & -0.016 & -0.008 & -0.016 & -0.026 & 0.002 \\
5 & -0.011 & -0.012 & -0.013 & -0.007 & -0.013 & -0.023 & 0.007 \\
6 & -0.007 & -0.008 & -0.010 & -0.004 & -0.010 & -0.021 & 0.012 \\
7 & 0.001 & 0.000 & -0.002 & 0.000 & -0.002 & -0.014 & 0.023 \\
8 & 0.012 & 0.010 & 0.008 & 0.011 & 0.008 & -0.006 & 0.038 \\
9 & 0.025 & 0.023 & 0.020 & 0.016 & 0.021 & 0.003 & 0.056 \\
10 & 0.050 & 0.047 & 0.045 & 0.018 & 0.045 & 0.021 & 0.093 \\
& & & & & & & \\
Total & -0.000 & -0.001 & -0.003 & -0.000 & -0.003 & -0.015 & 0.022 \\
\hline
\end{tabular}

Notes: "MSA" assumes vehicles in urban areas are driven throughout MSA. "PM 2.5 " includes damages from re-suspended particles. "Road" apportions own-county emissions to census block groups that are near major roads. "Subst" uses alternative forgone gasoline vehicles that are close engineering substitutes for each electric vehicle. "Prius" uses the Toyota Prius as the forgone substitute for all electric vehicles. "Mercedes" uses the Mercedes S550 as the forgone substitute for all electric vehicles.

\section{Efficiency: Electric Vehicle Purchase Subsidies and Location}

While received environmental benefits are appropriate for studying distributional effects of electric vehicle adoption, created environmental benefits are appropriate for analyzing the efficiency of government policy. In particular, we focus on electric vehicle purchase subsidies. All of the electric vehicles in our study qualify for a $\$ 7500$ federal purchase subsidy. In addition, many states provide additional purchase subsides. These state subsidies change frequently. We consider subsidies in place on July 28, 2014 and assume that all vehicle owners claim the federal subsidy as well as any applicable state subsidy 29 The combined state and federal subsidy per capita is determined by the sum of federal and state subsidies

\footnotetext{
${ }^{29}$ The list of subsidies by state used in our analysis comes from the online appendix to Holland et al., (2016). An up to date listing of state subsidies is given in http://www.afdc.energy.gov/laws/state.
} 
multiplied by the number of purchases in a county and then divided by county population (Figure 5). Subsidy per capita is quite large in a few counties around Atlanta, GA (Forsyth county leads the way with a remarkable per capita subsidy of $\$ 119$ ) and San Francisco, CA.

Figure 5: Subsidy (state and federal) per capita by county

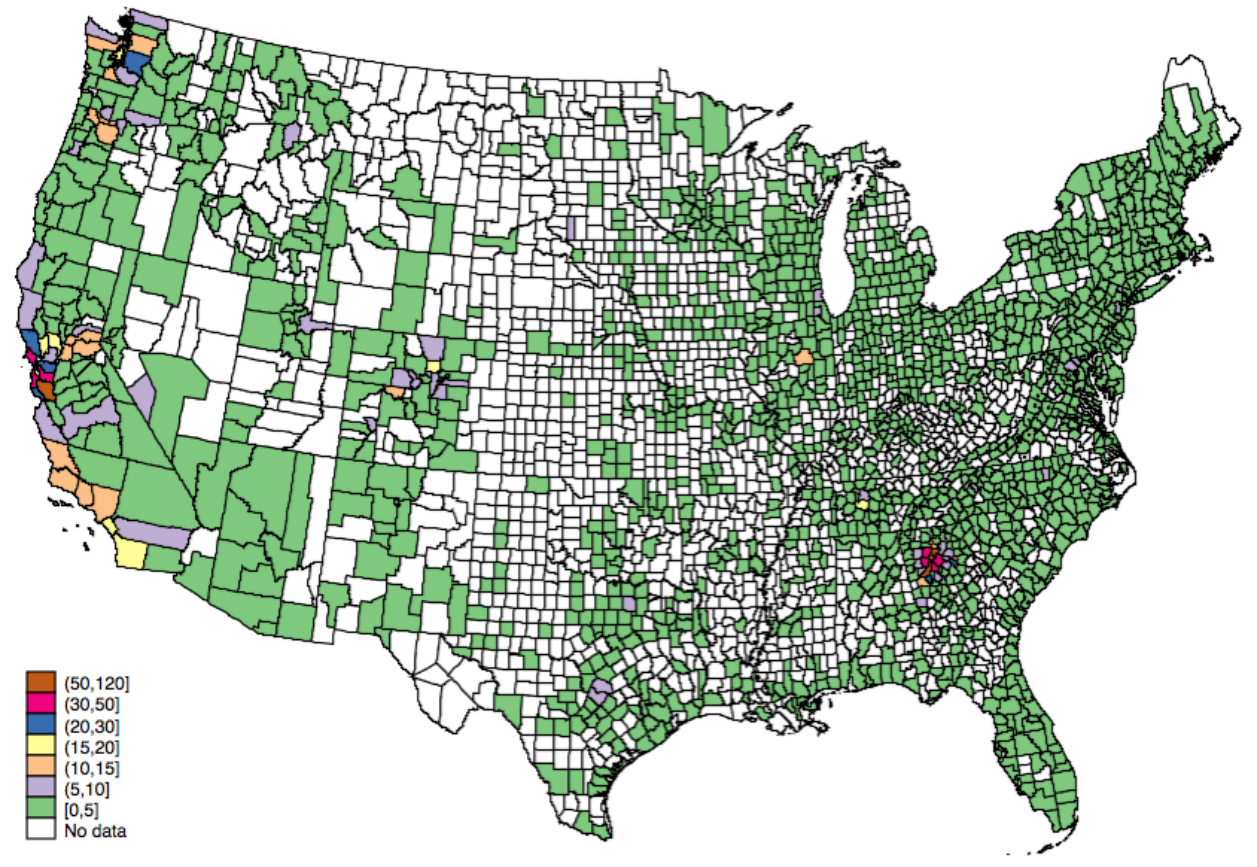

Figure 6 describes the relationship between the average lifetime environmental benefits created per vehicle registered in a given county and the per vehicle average of the aggregate subsidies across federal and state ${ }^{30}$ The scatter plot shows this relationship, where the size of the dot reflects the total volume of registered cars. For ease of viewing, we only report those counties that have over 100 registered electric vehicles. We see that Los Angeles and Santa Clara counties in California have many electric vehicles with positive environmental benefits but moderate subsidies per vehicle. In contrast, Fulton county in Georgia and McLean county in Illinois have larger subsidies but negative environmental benefits.

We also report the predictions based on a regression. Using data from all counties with electric vehicles, we regress the average lifetime environmental benefits created per vehicle registered in a given county on an indicator of whether there are state subsidies (in addition to the federal one) as well as a continuous variable of the level of the total subsidy ${ }^{31}$ We

\footnotetext{
${ }^{30} \mathrm{We}$ assume vehicles last for 10 years and thus have a 150,000 mile lifetime.

${ }^{31}$ We use frequency weights in the regression where we weight using a county's volume of registered vehicles
} 
Figure 6: Purchase Subsidies and Created Environmental Benefits

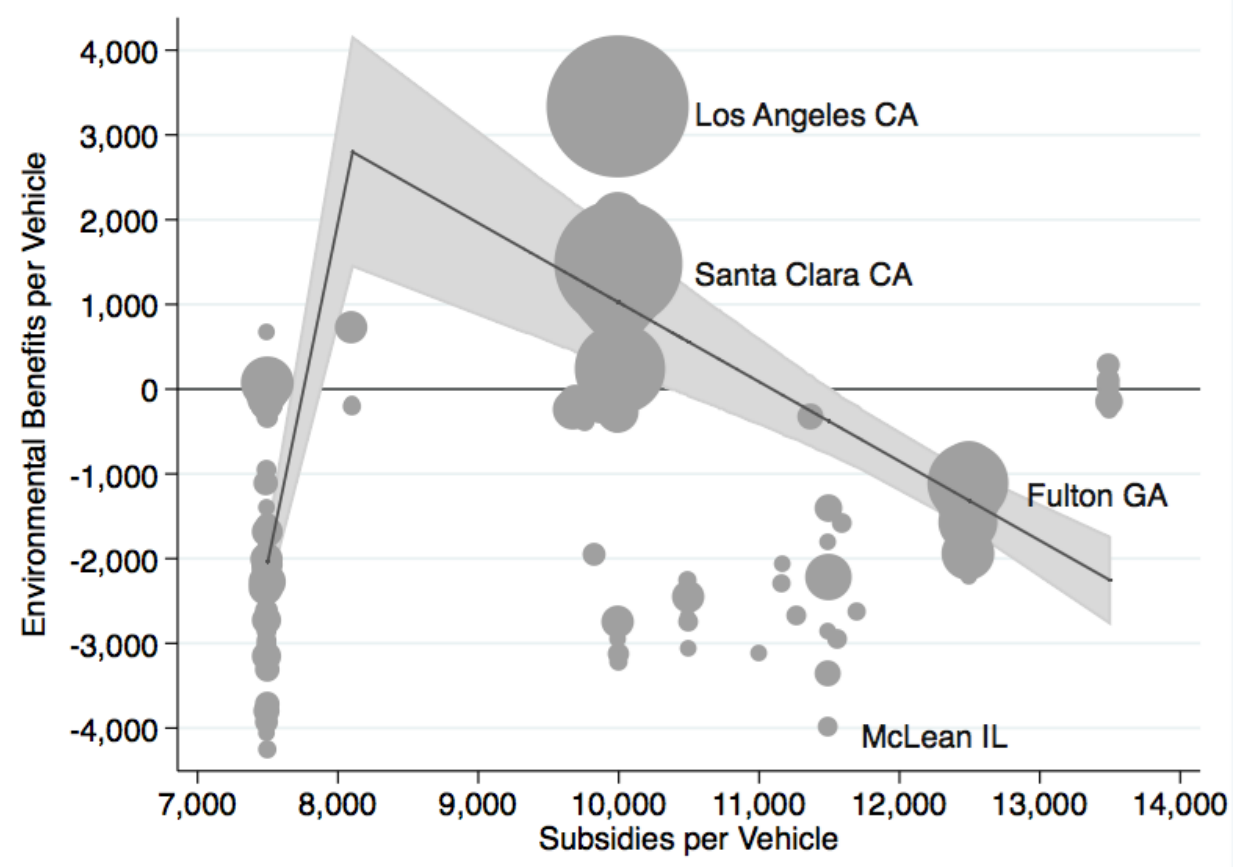

Notes: Environmental benefits are for all electric vehicles driving 15,000 miles per year for ten years. The scatter plot shows a county's environmental benefits per vehicle and the state and federal subsidies per vehicle, where the size is the volume of registered electric vehicles. Predictions from a linear model show the approximate relationship between benefits and subsidies. 
find that the model explains about half of the variation $\left(R^{2}=0.50\right)$ with a coefficient on the indicator of state subsidization of 5,404 (and a standard error of 806) and a coefficient on the level of the subsidy of -0.937 (0.163). Figure 6 reports the model's prediction and the $95 \%$ confidence interval. This regression is not meant to be interpreted as causal. Rather it is describing different relationships between environmental benefits of electric cars and subsidy choices. Counties with larger environmental benefits are more likely to be in states that offer local subsidies. However, the counties with the largest environmental benefits tend to be in states that offer smaller subsidies, and counties in states with the largest subsidies tend to have negative environmental benefits.

\section{Conclusion}

This paper explores the consequences of electric vehicle adoption for air quality and subsequent distributional effects. This entails a comparison between registered electric vehicles and forgone gasoline vehicles used in the same location. The outcomes of each vehicle are tracked using an integrated assessment model akin to the approach developed in Holland et al., (2016). An emphasis of the present work is, in contrast to much prior work in this area, the decomposition of impacts across space, across income groups, and across communities defined by racial and ethnic characteristics. We argue that this more nuanced tack is warranted for three reasons: (1) the large number of electric vehicles currently in use, (2) the heterogeneity in patterns of adoption rates across states, (3) the lack of knowledge about the characteristics of those who benefit from electric vehicle adoption. There appears that much is to be gained from an analysis that retains and exploits geographic detail relative to more aggregative work.

Our results show that the damages from air pollution due to driving our forgone gasoline vehicles generally increases with income, while the damages from air pollution due to driving electric vehicles is relatively constant with respect to income. Taking the difference reveals that census block groups with median income greater than about $\$ 67,000$ receive positive environmental benefits from electric vehicle adoption. There is strong evidence that census and cluster the standard errors by county. 
block groups with larger shares of Asian and Hispanic residents tend to receive greater environmental benefits. There is weaker evidence that block groups with a larger share Black residents tend to receive smaller environmental benefits.

Importantly, the patterns that we report may help to guide the design of electric vehicle policy in the future. For example, both the present work and prior research show that electric vehicles tend to be beneficial where the power grid is not predominantly fueled by coal. Thus, policy may improve welfare by encouraging electric vehicle adoption in areas of the country where the grid is fueled by natural gas and other, low-emission dispatchable resources. However, one implication of such a strategy appears to be concentrating benefits among Hispanic and Asian populations that congregate in the West where the grid is cleaner. In addition, earlier work highlights that damages from gasoline cars are highest in dense urban environments (Holland et al., 2016). On the surface, it would make sense to encourage electric vehicles use in such locales. However, our paper demonstrates that this tack primarily yields benefits to families with incomes well above the median income level.

How policymakers, academic researchers, and the general public weigh and rank these criteria in terms of their importance to policy design is clearly beyond the scope of the present paper. However, by focusing on received benefits, this analysis will infuse policy debates with a greater sense of the consequences of electric vehicle adoption. And, since electrification of the vehicle fleet may play an important role in future attempts to manage the environmental consequences of transportation, the present work is likely to have enduring value. 


\section{References}

[1] Amato, F., A. Karanasiou, T. Moreno, A. Alastuey, J. Orza, J. Lumbreras, R. Borge, E. Boldo, C. Linares, and X. Querol (2012), "Emission fators from road dust resuspension in a Mediterranean freeway," Atmospheric Environment 61: 580-587.

[2] Anderson, M. (2016), "As the wind blows: The effects of long-term exposure to air pollution on mortality," UCLA working paper.

[3] Archsmith, James, Alissa Kendal, and David Rapson. 2015. "From cradle to junkyard: Assessing the life cycle greenhouse benefits of electric vehicles." Research in Transportation Economics 52: 72-90.

[4] Babaee, Sameneh, Ajay S. Nagpure, and Joseph F. DeCarolis. 2014. "How much do electric drive vehicles matter to future U.S. emissions." Environmental Science and Technology 48: 1382-1390.

[5] Banzhaf, S. (2011), "Regulatory Impact Analyses of Environmental Justice Effects," Journal of Land Use and Environmental Law 27(1) 2011, pp. 1-30.

[6] Banzhaf, S., D. Burtraw, and K. Palmer (2006) "Efficient emission fees in the US electricity sector," Resource and Energy Economics 26: 371-341.

[7] Borenstein, S., and L. Davis (2016), "The distributional effects of U.S. clean energy tax credits," Tax Policy and the Economy, 30: 191-234.

[8] Fann, Neal, Charles M. Fulcher, and Bryan J. Hubbell. 2009. "The influence of location, source, and emission, type in estimates of the human health benefits of reducing a ton of air pollution." Air Quality, Atmosphere and Health 2: 169-176.

[9] Gosh, R., F. Lurman, L. Perez, B. Penfold, S. Brandt, J. Wilson, M. Milet, N. Kunzli, R. McConnell, "Near-roadway air pollution and Coronary Heart Disease: Burden of disease and potential impact of a greenhouse gas reduction strategy in Southern California," Environmental Health Perspectives 124: 193-200. 
[10] Graff Zivin, Joshua S.,, Matthew Kotchen, and Erin T. Mansur. 2014. "Spatial and temporal heterogeneity of marginal emissions: Implications for electric cars and other electricity-shifting policies." Journal of Economic Behavior and Organization 107 (A): 248-268.

[11] Grissom, Gregory. 2013. "Determining the optimal subsidy for plug-in electric vehicles in the United States by county," Honors Thesis in Economics, The University of North Carolina at Chapel Hill.

[12] Health Effects Institute (2010), Special Report 17: Traffic related air pollution: A critical review of the literature on emissions, exposure, and health effects, Boston Massachusetts.

[13] Holland, S., E. Mansur, N. Muller, and A. Yates (2016), "Are there environmental benefits from driving electric vehicles? The importance of local factors," forthcoming American Economic Review.

[14] Li, Shanjun, Lang Tong, Jianwei Xing, and Yiyi Zhou (2015), "The market for electric vehicles: Indirect network effects and policy design." http://dx.doi.org/10.2139/ssrn.2515037

[15] Jenn, Alan, Ines M. L. Azevedo and Jeremy J. Michalek (2016), "Alternative fuel vehicle adoption increases fleet gasoline consumption and greenhouse gas emissions under United States corporate average fuel economy policy and greenhouse gas emissions standards." Environmental Science and Technology, DOI: 10.1021/acs.est.5b02842.

[16] Karner, A, D. Eisinger, and D. Niemeier (2010), "Near-roadway air quality: Synthesizing the findings from real-world data," Environmental Science and Technology 44: 53345344.

[17] Mendelsohn, Robert O. 1980. "An economic analysis of air pollution from coal-fired power plants." Journal of Environmental Economics and Management 7 (1): 30-43.

[18] Michalek, Jeremey J., Mikhail Chester, Paulina Jaramillo, Constantine Samaras, ChingShin Norml Shiau, and Lester B. Lave. 2011. "Valuation of plug-in vehicle life-cycle 
air emissions and oil displacement benefits." Proceedings of the National Academy of Sciences 108: 16554-16558.

[19] Muller, Nicholas Z. 2011. "Linking policy to statistical uncertainty in air pollution damages." The B.E. Press Journal of Economic Analysis and Policy 11 (1) Contributions, Article 32.

[20] Muller, Nicholas Z. and Robert O. Mendelsohn (2009), "Efficient pollution regulation: getting the prices right." American Economic Review 99: 1714-1739.

[21] Rowangould, G. (2013), "A census of the US near-roadway population: Public health and environmental justice considerations," Transportation Research Part D 25: 59-67.

[22] Yuksel, T., M. Tamayao, C. Hendrickson, I. Azevedo, and J. Michalek (2016), "Effect of regional grid mix, driving patterns and climate on the comparative carbon footprint of gasoline and plug-in electric vehicles in the United States," Environmental Research Letters 11, doi:10.1088/1748-9326/11/4/044007.

[23] Tessum, Christopher W., Jason D. Hill, and Julien D. Marshall. 2014. "Life cycle air quality impacts of conventional and alternative light duty transportation in the United States." Proceedings of the National Academy of Sciences 111: 18490-18495.

[24] Timmers, V. and P. Achten (2016), "Non-exhaust PM emissions from electric vehicles," Atmospheric Environment 134: 10-17. 


\section{Appendix}

\section{Electricity Regions}

For electric vehicles, we divide the country into nine electricity load regions. A vehicle charged in any county within in a given region leads to the same response from the grid. This response may include emissions from electricity plants that are in other regions as the electricity supply and demand are balanced within and across regions. Figure A-1 maps our nine electricity load regions: California (CA); Electric Reliability Council of Texas (ERCOT); Florida Reliability Coordinating Council (FRCC); Midwest Independent System Operator and Midwest Reliability Organization (MISO \& MRO); Northeast Power Coordinating Council (NPCC); ReliabilityFirst Corporation (RFC); SERC Reliability Corporation (SERC); Southwest Power Pool, RE (SPP); Western Electricity Coordinating Council except California (WECC).

Figure A-1: Map of Electricity Load Regions

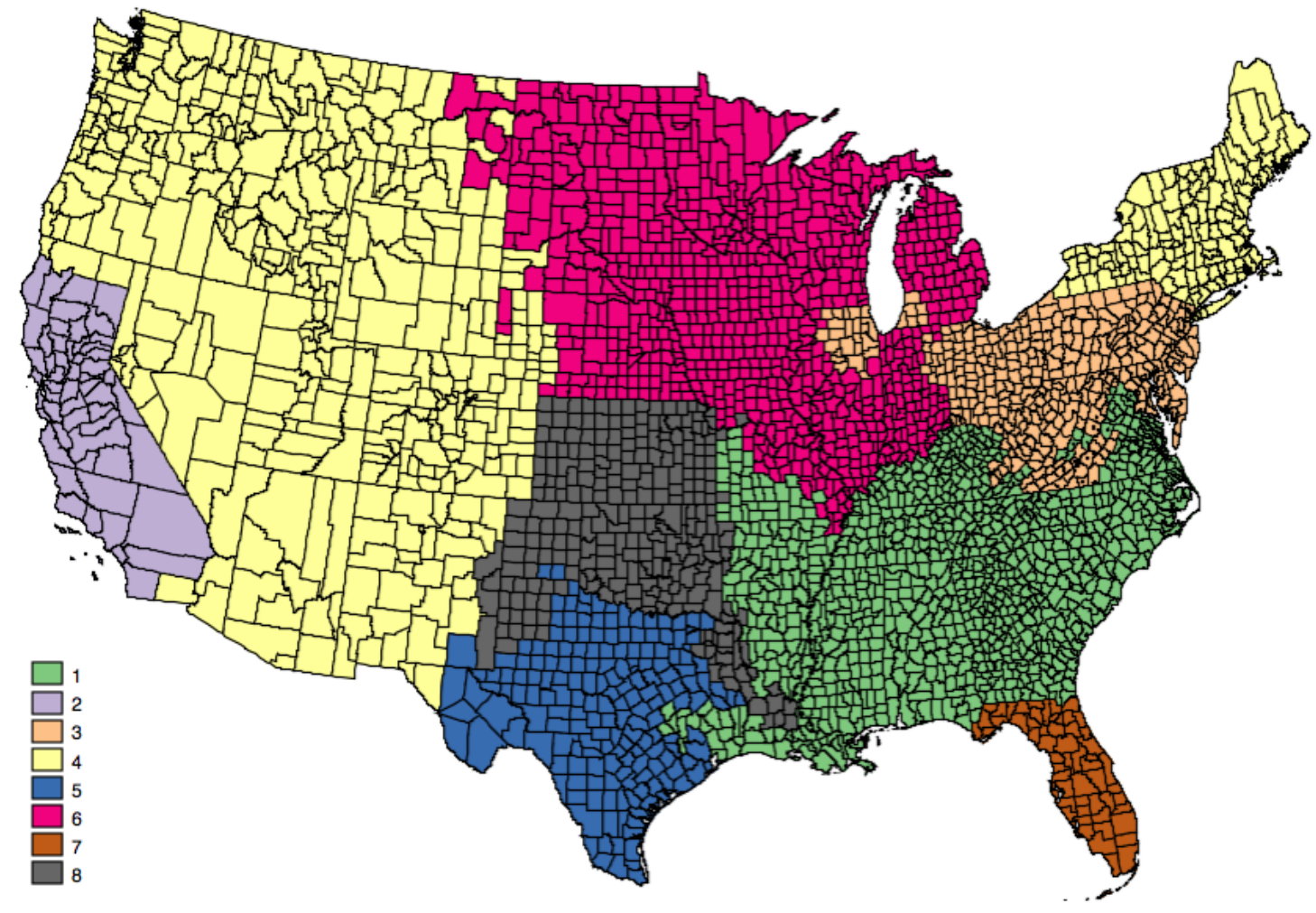

Notes: Codes are 1-SERC; 2-California; 3-RFC; 4-WECC w/o CA or NPCC; 5-ERCOT; 6-MISO \& MRO; 7-FRCC; and 8-SPP. 


\section{Cumulative Distribution Functions For Air Pollution Damages From Driving}

Figure 3 shows the Lorenz curves for electric vehicle and gasoline vehicle damages. The Lorenz curve is useful for calculating the Gini coefficient, which is a univariate measure of concentration. However, this measure is problematic here for two reasons. First, we are interested in the environmental benefits to different demographic groups. As a univariate measure, the Lorenz curves cannot illustrate relationships between variables. Second, the Lorenz curves in Figure 3 are somewhat misleading since the cumulative fraction of income, gasoline vehicle damages, or electric vehicle damages is calculated relative to the cumulative fraction of the population sorted by each variable, i.e., the x-axis is resorted for each Lorenz curve. Thus a person who receives high gasoline vehicle damages (and be close to one on the $\mathrm{x}$-axis for that Lorenz curve) may receive low electric vehicle damages (and be close to zero on the $\mathrm{x}$-axis for that Lorenz curve).

A generalized Lorenz curve addresses both of these concerns by allowing for a common sorting along the $\mathrm{x}$-axis based on any variable. Figure A-2 shows the generalized Lorenz curves for environmental damages due to driving gasoline and electric vehicles relative to income. Here the $\mathrm{x}$-axis is sorted by income and the curves measure the cumulative share of environmental damages that accrue to people at or below that percentile of the income distribution. For examplle, the figure shows that the people with incomes below the median (the poorest $50 \%$ of the population) receive more than $\$ 10$ million in damages from the electric vehicle fleet, but would have received less than $\$ 10$ million from the avoided gasoline vehicle fleet. Thus, the poorest $50 \%$ of the population are harmed in aggregate by electric vehicles.

Figure A-2 shows that although in aggregate the environmental benefits of electric vehicles are basically zero (i.e., the curves are the same at one), the burden is not equally distributed across the income distribution. However, Figure A-2 cannot show whether the environmental benefit is increasing in income (the slope of these curves) or the income at which the environmental benefit switches from negative to positive. Figure 4 illustrates the kernal density (essentially the slopes of the curves in Figure A-2 to show that the environ- 
mental benefit is indeed increasing in income and to illustrate the cross-over point where environmental benefit switches from negative to positive.

Figure A-2: Cumulative Distributions: Air Pollution Damages from Driving

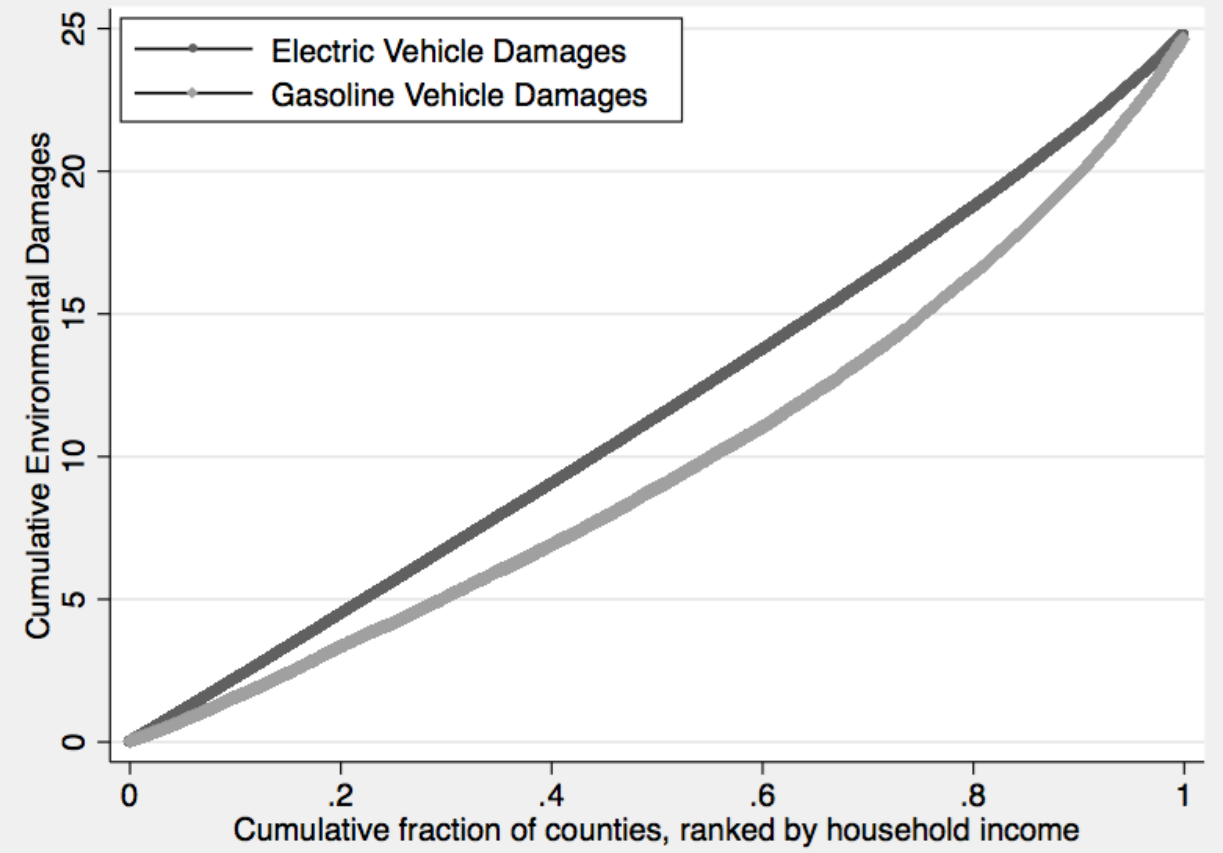

Notes: Horizontal axis is cumulative fraction of census block groups ranked by income. Vertical axis is cumulative fraction of the relevant variable (electric vehicle damages, gasoline vehicle damages). Damages are for all cars in the fleet driving $15 \mathrm{k}$ miles per year.

\section{Regional Variation in the Distributional Effects of Electric Vehicles}

There is substantial regional variation in the environmental benefit of electric vehicles. Similarly, their may be regional variation in the distributional effects of electric vehicles. To assess regional variation, we split our sample into the West census region and "Non-West" made up of the Northeast, Midwest, and South census regions. We then redo our analysis for the two subsamples. Table A-1 shows the results from Model (8) in Table 7 for both the full sample and for the split sample. The column in Table A-1 labeled "All" replicates the earlier results, and the other columns show results for the split sample. The results are quite robust to splitting the sample. Somewhat surprisingly, the results are stronger in the West (where electricity production is cleaner) than in the Non-West. Thus cleaner electricity production may not alleviate concerns over distributional effects of electric vehicles. 
Table A-1: Descriptive Regressions of Environmental Benefits Received per Capita by Region

\begin{tabular}{crrr}
\hline & All & West & Non-West \\
\hline & & & \\
Income (10k) & $0.011^{* * *}$ & $0.024^{* * *}$ & $0.003^{* * *}$ \\
& $(0.003)$ & $(0.004)$ & $(0.001)$ \\
Urban Indicator & $0.019^{* * *}$ & $0.056^{* * *}$ & $0.015^{* * *}$ \\
& $(0.005)$ & $(0.021)$ & $(0.003)$ \\
Share White & $-0.164^{* * *}$ & $-0.301^{* * *}$ & $-0.056^{* * *}$ \\
& $(0.042)$ & $(0.050)$ & $(0.010)$ \\
& & &
\end{tabular}

Notes: Dependent variable is environmental benefit per capita. WLS regressions weight by total population and cluster standard errors by county. "West" is the West census region. "Non-West" is the Midwest, Northeast, and South census regions. 